\title{
Zoonotic and vector-borne parasites and epilepsy in low-income and middle-income countries
}

Gagandeep Singh ${ }^{1,2}$, Samuel A. Angwafor ${ }^{2}$, Alfred K. Njamnshi ${ }^{3,4}$, Henry Fraimow ${ }^{5}$ and Josemir W. Sander $2,6,7 \dagger$

${ }^{1}$ Department of Neurology, Dayanand Medical College, Ludhiana, India.

${ }^{2}$ NIHR University College London Hospitals Biomedical Research Centre, UCL Queen Square Institute of Neurology; London WC1N 3BG, UK.

${ }^{3}$ Neurology Department, Central Hospital Yaoundé/Neuroscience Lab, Faculty of Medicine and Biomedical Sciences (FMBS), The University of Yaoundé 1, Yaoundé, Cameroon.

${ }^{4}$ Brain Research Africa Initiative (BRAIN), Geneva, Switzerland and Yaoundé, Cameroon. ${ }^{5}$ Division of Infectious Diseases, Cooper Medical School of Rowan University, Camden, NJ, USA.

${ }^{6}$ Chalfont Centre for Epilepsy, Chalfont St Peter, Buckinghamshire, UK.

${ }^{7}$ Stichting Epilepsie Instellingen Nederland (SEIN), Heemstede, Netherlands.

†e-mail: l.sander@ucl.ac.uk

Abstract | Zoonotic and vector-borne parasites are important preventable risk factors for epilepsy. Three parasitic infections, cerebral malaria, Taenia solium cysticercosis and onchocerciasis, have an established association with epilepsy. The parasitoses are widely prevalent in low-income and middle-income countries, which are home to $80 \%$ of the people with epilepsy in the world. Once a parasitic infection has taken hold in the brain, therapeutic measures do not seem to influence the development of epilepsy in the long term.

Consequently, strategies to control, eliminate and eradicate parasites represent the most feasible way to reduce the epilepsy burden at present. The elucidation of immune 
mechanisms underpinning the parasitic infections, some of which are parasite-specific, opens up new therapeutic possibilities. In this Review, we explore the pathophysiological basis of the link between parasitic infections and epilepsy, and we consider preventive and therapeutic approaches to reduce the burden of epilepsy attributable to parasitic disorders. We conclude that a concerted approach involving medical, veterinary, parasitological and ecological experts, backed by robust political support and sustainable funding, is the key to reducing this burden.

\section{[H1] Introduction}

Epilepsy is a serious neurological disorder that affects at least 50 million people globally ${ }^{1}$. This condition imposes a substantial disability burden owing to premature mortality and years lived with seizures in individuals in whom seizures are not controlled ${ }^{2,3}$. A considerable amount of this burden is potentially preventable, but the prospects for prevention have not yet been sufficiently explored ${ }^{4}$. In 2015, the WHO adopted a resolution urging member states to promote epilepsy prevention using evidence-based interventions, within and outside the health sector ${ }^{5}$. To enable such a strategy, preventable risk factors for epilepsy need to be identified.

The preventable risk factors for epilepsy are mainly restricted to CNS infections, stroke, perinatal brain insults and traumatic brain injury ${ }^{4}$. Parasitic disorders constitute an important subgroup among the various CNS infections. These disorders include zoonoses that are transmitted from animals to humans, such as taeniasis-cysticercosis, toxocariasis and toxoplasmosis, and vector-borne parasitic disorders, such as malaria, onchocerciasis and trypansomaiasis (TABLE 1$)^{6}$. The majority of zoonotic and vector-borne parasitoses are highly prevalent in — though not restricted to — resource-limited settings (FIG. 1) ${ }^{7}$. The 
existing socioeconomic climate, ecological conditions and widespread political uncertainty in these regions contributes to the continuing occurrence of parasitic disorders.

A large body of evidence has linked epilepsy to zoonotic and vector-borne parasitoses in low-to-middle-income countries (LMICs), and the high incidence of epilepsy in these countries has often been attributed to the prevailing CNS infections ${ }^{8}$. Considerable variations in the prevalence of epilepsy have been reported between different regions in LMICs, some of which might be explained by ecological, sociocultural and economic factors. For instance, in onchocerciasis-endemic regions in Sub-Saharan Africa (SSA), the prevalence of epilepsy increases with proximity to rivers, probably because Onchocerca volvulus, a parasite ostensibly associated with epilepsy, is transmitted by a blackfly that breeds near rivers ${ }^{9}$. Similarly, epilepsy related to Taenia solium cysticercosis, which is often acquired through ingestion of contaminated food, might be frequent in pig-rearing communities within $\mathrm{LMICs}^{10}$.

International attention, funding opportunities and unprecedented local initiatives have fuelled renewed interest in the association between zoonotic and vector-borne parasites and epilepsy, and a comprehensive examination of this complex link is long overdue. In this article, we review the pathophysiological basis of this association and assess the resulting disease burden. We also consider prospects for reducing this burden, with an emphasis on epilepsy prevention, and discuss how research into the underlying immune mechanisms might drive the development of new therapies.

\section{[H1] Fundamental nosological considerations}

The parasitic disorders that we discuss in this Review vary considerably in terms of onset, clinical manifestations and trajectories. Cerebral malaria is a prototype of an acute encephalitic disorder that carries a high risk of seizures and status epilepticus and produces 
long-term neurological sequelae in $\sim 10 \%$ of cases ${ }^{11}$. Neurocysticercosis is a chronic disorder caused by $T$. solium, which presents with seizures in over two-thirds of cases and subsequently has an unpredictable course ${ }^{12,13}$. The onset of neurological illness associated with onchocerciasis is difficult to determine ${ }^{9}$.

In most parasitic disorders, seizures and status epilepticus may occur during the active phase of cerebral infection ${ }^{14}$. Late unprovoked seizures in the setting of CNS parasitic infection constitute epilepsy ${ }^{15}$. The distinction between epilepsy and early, provoked seizures is important but is sometimes difficult, for example, in neurocysticercosis when multiple cysts at different stages of evolution coexist ${ }^{16}$. For most parasitic infections, the interval between the initial precipitating insult and the occurrence of late unprovoked seizures presumably the time period for epileptogenesis to develop — is long and unpredictable. From the prevention standpoint, interventions applied during or immediately after active infection might limit cerebral damage and possibly interrupt or modify epileptogenesis. These interventions constitute secondary preventive measures against the development of epilepsy $y^{4}$. Conversely, interventions to control, eliminate or eradicate parasitic disorders amount to primary prevention of epilepsy.

Secondary preventive measures remain elusive but present attractive opportunities for current and future research. Most of these opportunities derive from the inflammatoryimmunological underpinnings of seizures and epilepsy ${ }^{17,18}$. Several experimental and human studies have established that inflammation follows acute and new cerebral insults but is also sustained long after the insults cease ${ }^{19-21}$. Zoonotic and vector-borne parasitic infections of the brain present a convenient and natural opportunity to study inflammatory pathways and to conceptualize, test and validate novel therapies to interfere with these pathways, thereby halting epileptogenesis and improving overall outcomes ${ }^{18,22,23}$. 


\section{[H1] Malaria}

\section{[H2] Epidemiology}

Malaria, which is transmitted to humans by the bite of the female Anopheles mosquito, is a major public health concern, particularly in Africa, Asia and South America (FIGS 1, 2) ${ }^{24}$. Five forms are recognized, of which two, Plasmodium vivax and P. falciparum malaria (FIG. 2), are most common.

Estimates of the burden and disability associated with malaria vary from source to source, mainly owing to methodological differences ${ }^{3}$. The World Malaria Report estimated 219 million cases worldwide in 2017, of which 90\% were from the WHO African Region ${ }^{25}$. Taken together, 15 countries in SSA and India account for nearly $80 \%$ of the cases (FIG. 1). According to data from the Oxford-based Malaria Atlas Project, the incidence of, and mortality attributed to falciparum malaria declined considerably between 2005 and 201726,27. Analysis of data from both sources indicates that substantial gains were made in terms of malaria control in the first few years of this period, but progress seemed to slacken over the past decade. Besides numerical gains, the geographical distribution of malaria has become more restricted over the past two decades. The spatial contraction is substantial but seems restricted to Asia and South America, having eluded SSA where about half a billion people remain at risk of malaria exposure. The decreasing returns over the past decade have raised concerns over the prospects of eradicating malaria in the region. The likelihood of eradication is also threatened by malaria resurgence, driven by growing vector resistance to insecticides ${ }^{28}$. Many regions in Africa have also experienced an increase in malaria incidence in the wake of strife and political instability ${ }^{29}$.

\section{[H2] Clinical manifestations}


$P$. falciparum is responsible for the most severe clinical manifestations of malaria.

Uncomplicated malaria is characterized by fever with chills but sparing vital organs from express clinical involvement. Complicated malaria occurs when the parasitized red blood cells are sequestered within the microcirculation, leading to release of pro-inflammatory cytokines and endothelial damage ${ }^{11,30}$. This condition is characterized by severe anaemia, impending or overt respiratory failure and/or coma.

Cerebral malaria is the most serious complication of falciparum malaria, typically manifesting with hyperpyrexia, coma, seizures and status epilepticus, and is often fatal ${ }^{11,31,32}$. Cerebral malaria mainly occurs in children under 5 years of age, probably owing to low immunity levels in this age group ${ }^{11,33}$. A diagnosis of cerebral malaria is contingent on the demonstration of asexual forms of $P$. falciparum in blood smears and the exclusion of alternative causes of a febrile coma. As asymptomatic peripheral blood parasitaemia is well known in SSA on account of immunity, the mere demonstration of the parasite in blood smears might not be sufficient to establish diagnosis ${ }^{34}$. An autopsy study from Malawi showed that seven of 31 children with clinically diagnosed cerebral malaria died from other cause $^{35}$. In this regard, the finding of a cerebral malaria-specific retinopathy is a useful diagnostic marker of disease that also correlates well with severity ${ }^{36,37}$.

Falciparum malaria episodes are frequently associated with seizures and status epilepticus $^{31,32,38}$, especially in Africa. As malaria predominantly afflicts children under 5 years of age, these episodes might be passed off as febrile seizures ${ }^{11}$. Seizures in malaria episodes, however, are frequently focal and prolonged and hence can be differentiated from simple febrile seizures.

Case fatality rates in cerebral malaria of up to $20 \%$ have been reported from SSA ${ }^{33,39}$. Survivors have high rates of long-term neurological morbidity, including seizures, cognitive impairment, neuropsychiatric sequelae and focal neurological deficits ${ }^{40}$. A meta-analysis 
identified six reports, which included epilepsy as an outcome following an episode of cerebral malaria $^{41}$. These studies had been undertaken in Mali, Malawi, Gabon, Kenya and Uganda in the previous two decades. They mostly had small samples and were either prospective or retrospective exposed-unexposed cohort or case-control studies. Follow-up varied between 18 and 72 months $s^{36,42-46}$. The pooled odds ratio for the occurrence of unprovoked seizures was 4.7 (95\% CI 2.5-8.7) $)^{41}$.

\section{[H2] Pathophysiology of cerebral malaria}

Our current understanding of the pathophysiology of cerebral malaria is largely based on a small number of human autopsy reports and findings from models of $P$. berghei infection in C57BL/6J mice ${ }^{47}$. The key processes that were elucidated in these studies were cytoadherence of the parasitized erythrocytes and inflammation ${ }^{48,49}$. Sequestration of parasitized erythrocytes in the cerebral microvasculature produces clinical symptoms, highlighting the pathogenic role of cytoadherence ${ }^{50}$. Evidence is also mounting for the involvement of inflammatory mediators such as tumour necrosis factor, intracellular adhesion mediator-1 and angiopoietin-2 in the initiation of endothelial damage in the cerebral blood vessels $^{51-54}$. The upregulated inflammatory markers correlate well with the occurrence of malaria-specific retinopathy ${ }^{53}$. These findings provide a rationale for testing novel cellular and molecular agents, including a range of monoclonal antibodies, in the primary management of cerebral malaria, with the objective of reducing long-term neurological complications (TABLE 2).

\section{[H2] Treatment and prevention}

Current treatment of uncomplicated malaria comprises artemisinin-based combination therapy, whereas treatment of cerebral malaria requires intravenous administration of the 
antimalarial drug, artesunate ${ }^{39}$. This latter intervention results in prompt resolution of coma and prevents mortality in acute episodes, but the impact of acute treatment on long-term neurological morbidity, including epilepsy, is not known.

Antiseizure medications have also shown some benefits in people with cerebral malaria. Two randomized controlled trials, one conducted in Thailand and the other in Kenya, assessed the effects of a single dose of phenobarbital on the incidence of convulsions and mortality in cerebral malaria ${ }^{55,56}$. Both trials demonstrated significant reductions in the incidence of convulsive seizures. The Kenyan study, however, suggested increased mortality in the phenobarbital-treated $a^{5}{ }^{55}$. Enteral levetiracetam could be a safer option ${ }^{57}$. Administration of antiseizure medications during cerebral malaria episodes does not offer any protection against the development of neurological deficits ${ }^{58}$ and the impact of these drugs on the development of later epilepsy has not been evaluated ${ }^{55-58}$. Besides antimalarials and phenobarbital, few therapeutic agents have been assessed in human interventional trials for the treatment of cerebral malaria. As outlined in the previous section, several potential experimental agents have emerged from research into the pathogenesis of cerebral malaria.

As the impact of secondary preventive measures on the development of epilepsy remains unproven, primary prevention of malaria is currently the only practical option to reduce the burden of epilepsy associated with this condition. A large body of evidence supports the use of long-lasting impregnated bed nets and indoor residual spraying to prevent

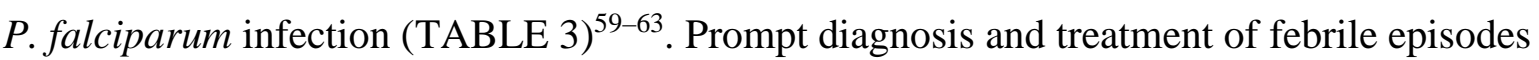
also seems to prevent the development of cerebral malaria. The combination of measures has been successful in controlling and even eliminating malaria in some regions, but global eradication remains an elusive goal ${ }^{64}$. The history of medicine is replete with instances of malaria resurgence following near successes ${ }^{29}$. Analyses of these re-emergence episodes, including data from the Global Malaria Eradication Programme, suggest that lack or 
withdrawal of funding is the most common reason for failure, but vector resistance to insecticides, agent resistance to antimalarials and political uncertainty, and conflict are also important factors. History reminds us that control and sustained elimination efforts will need continued financial support, political commitment, advocacy and efficient organization.

Several gaps remain in our understanding of the relationship between epilepsy and malaria. Only a few reports of MRI and neuropathological evaluations in acute cerebral malaria episodes are available and none has focused on long-term sequelae such as epileps ${ }^{65-68}$. The epileptogenic substrates associated with cerebral malaria are also yet to be fully clarified. The impact of several potential therapeutic agents that could be administered during or immediately after the cerebral malaria episode on the development of epilepsy and other neurological sequelae merits further investigation (TABLE 2).

\section{[H1] Taenia solium neurocysticercosis}

\section{[H2] Epidemiology}

$T$. solium cysticercosis is caused by ingestion of $T$. solium eggs as a result of eating contaminated food or drinking contaminated water, and is endemic in many parts of SSA, Latin America and South and Southeast Asia (FIG. 1) ${ }^{69}$. Several ecological factors in these regions are responsible for sustaining the life cycle of the worm (FIG. 2). A lack of access to basic sanitation (specifically, latrines) and the presence of free-ranging pigs (as opposed to penned pigs) that feed on human faeces are risk factors for porcine cysticercosis. Deficient meat inspection and widespread consumption of raw or undercooked pork infested by cysticerci leads to human taeniasis. Inexistent or poor basic sanitation and lack of personal hygiene are risk factors for human cysticercosis.

The WHO ranks T. solium fourth in the list of 31 food-borne hazards contributing to the global burden of disease ${ }^{70}$. Between 2007 and 2015, T. solium infection was responsible 
for 2.8 million disability-adjusted life years (DALYs) and over 28,000 deaths. Traditionally, attention to this parasite has focused largely on Latin America, where it accounts for nearly one-fifth of the region's aggregate disease burden. It is now recognized that the African nations harbour almost two-thirds of the global burden associated with T. solium infection (FIG. 1). The extent of T. solium infection in Africa is only just becoming apparent and might have previously been underestimated owing to a lack of awareness of the disease and/or a dearth of diagnostic facilities. A recent increase in pig rearing in this region, coupled with lack of access to adequate sanitation and basic living conditions, could also underlie the emergence of $T$. solium.

\section{[H2] Clinical manifestations}

In humans, cysticerci can be found in many tissues, but infestation of the brain, known as neurocysticercosis, most often produces clinical manifestations. The cysts can lodge in various brain compartments, but most frequently in the cerebral parenchyma, and go through evolutionary stages from live active cysts to fibro-calcified residues via a transitional stage ${ }^{71}$. The transitional and fibro-calcified stages are most often associated with seizures ${ }^{16}$.

The disability burden and much of the premature mortality associated with $T$. solium infection is largely accounted for by epilepsy ${ }^{70}$. Seizures are the presenting manifestation in nearly $80 \%$ of cases of $T$. solium neurocysticercosis ${ }^{13}$. Apart from seizures, neurological manifestations might include — but are not limited to — headache, cognitive impairment, focal neurological deficits and raised intracranial pressure. Worldwide, neurocysticercosis is one of the main risk factors for acquired epilepsy ${ }^{16}$. In endemic countries where populationbased studies have been conducted, neurocysticercosis accounts for nearly one-third of all cases of epilepsy ${ }^{72-75}$. 


\section{[H2] Pathophysiology}

Degenerating and dying brain parenchymal cysticerci trigger local host inflammatory responses involving many different inflammatory cell types including lymphocytes, macrophages and plasma cells ${ }^{76,77}$. Human and animal studies have shown that the cellular inflammation is associated with varying degrees of upregulation of cytokine expression involving the T helper $1\left(\mathrm{~T}_{\mathrm{H}} 1\right)$ and $\mathrm{T}_{\mathrm{H}} 2$ cell pathways ${ }^{78,79}$. Cytokine upregulation has been shown to correlate with clinical symptoms, including seizures ${ }^{80}$. Thus, evidence points towards a range of immune mechanisms and effector molecules, some of which might be involved in the pathogenesis of seizures and epilepsy. The elucidation of these mechanisms raises the prospect of developing novel therapies directed towards the immune processes or molecules involved. Genes and genetic mechanisms underpinning the immunological reactions to the parasite are now also being uncovered ${ }^{81,82}$, This opens up the possibility of identifying infected individuals or populations who are particularly susceptible to seizures and epilepsy.

The fibro-calcified neurocysticercus nodule is the focus for the ongoing epileptogenicity and, hence, an enduring propensity to seizures ${ }^{83}$. In one study of people with calcified neurocysticercosis, the occurrence of seizures was temporally linked to perilesional oedema around the calcified nodule, as identified on MRI, in roughly half of the cases ${ }^{84}$. The perilesional oedema presumably represents an inflammatory reaction to cyst components released intermittently and unpredictably from the calcified nodule $e^{85,86}$. The basis of seizures in calcified nodules without perilesional oedema remains speculative — an inflammatory component could exist but has so far eluded detection by conventional imaging. Calcified nodules, either with or without perilesional oedema, represent suitable targets for a variety of potential agents to reduce the burden of seizures (TABLE 2). 


\section{[H2] Treatment and prevention}

T. solium is estimated to account for at least $5 \%$ of all preventable epilepsies on a global scale ${ }^{4}$. In theory, epilepsy associated with neurocysticercosis should be amenable to secondary and primary prevention.

From the perspective of secondary prevention of seizures and epilepsy in brain parenchymal cysticercosis, three classes of pharmacological agents have been assessed: antiseizure medications, antihelminthic drugs (albendazole and praziquantel) and corticosteroids. The use of antiseizure medications is recommended in all people with neurocysticercosis who have seizures ${ }^{87}$. None of the currently used antiseizure medications are antiepileptogenic and their use should be avoided in individuals with neurocysticercosis who have never experienced seizures.

Antihelminthic agents have a favourable impact on cyst resolution in active parenchymal cysticercosis ${ }^{88-90}$, but their role in preventing seizures in people with neurocysticercosis is difficult to ascertain. The available randomized controlled trials of antihelminthic treatment are mostly of short duration and have demonstrated a reduction in the number of seizures over 6-24 months ${ }^{88-90}$. One trial suggested that the effects of antihelminthic drugs depend on the seizure type, with reduced numbers of generalized but not focal seizures with treatment ${ }^{89}$. Complete seizure remission, which is the standard goal in treating epilepsy, remained elusive in many cases.

The long-term impact of antihelminthic drugs on seizure recurrence is uncertain. Seizure remission might depend on the complete disappearance of all cysticerci following antiheminthic treatment; however, in conventional treatment trials of antihelminthic agents, resolution of cysticerci was observed in less than two-thirds of individuals ${ }^{77-79}$. Regardless of whether antihelminthic treatment is administered, many of the cysticerci evolve to calcified residue, which provides a substrate for ongoing seizures (or active epilepsy) in the 
setting of cerebral parenchymal neurocysticercosis ${ }^{83,84,91}$. Hence, many individuals continue to have seizures in the long term despite the administration of antihelminthic treatment, as confirmed in a causal model of seizures associated with neurocysticercosis ${ }^{92}$.

Several trials and meta-analyses have demonstrated beneficial effects of corticosteroid administration, especially in solitary cerebral parenchymal cysticercosis ${ }^{93,94}$, but the longterm effects of this treatment on seizure outcomes have not been defined.

Primary prevention of $T$. solium cysticercosis entails a shift of focus from the clinic to the community. The International Task Force for Disease Eradication recommends community-led total sanitation as the prime measure in the control or elimination of cysticercosis $^{95}$. Improved sanitation with closed toilets as opposed to open defecation is thought to prevent contamination of the environment with $T$. solium eggs, from which freeranging pigs can become infected (FIG. 3). Globally, 1.2 billion people, mostly in a handful of LMICs, still practise open defecation ${ }^{96}$. Efforts towards improved sanitation are in keeping with United Nations Sustainable Development Goal 6 (provision of clean water and sanitation) and evidently offers added health benefits ${ }^{97}$. Interventions to improve toilet coverage across different regions of the world have met with limited success, as the mere construction of toilets does not ensure that they are used ${ }^{98}$. Innovative approaches emphasizing sustained behavioural change with the use of affordable and efficient technology are clearly required ${ }^{99}$.

Besides improved sanitation, a number of secondary approaches to the prevention of T. solium have been developed and implemented (TABLE 1). A comprehensive initiative in Peru over nearly a decade, comprising porcine chemotherapy and vaccination, human tapeworm treatment and health education, achieved reasonable success ${ }^{100,101}$. The complexity and large scale of this intervention could constitute a barrier to effective implementation in other regions. Health education is arguably a crucial approach but was ineffective in an early 
community experiment ${ }^{102}$. More recently, innovative approaches using mobile device technology have met with preliminary success in Africa ${ }^{103,104}$. Community education that is capable of engendering enduring change in the mindsets of people is likely to be the key to successful control and elimination of cysticercosis.

Despite the accumulated information from several clinical trials and public health experiments, substantial gaps remain in our approaches to treatment and control of cysticercosis. Long-term seizure outcomes in individuals with cerebral parenchymal cysticercosis, naturally and after treatment with antihelminthic drugs, remain to be determined. Currently, conventional antihelminthic regimens produce resolution rates of up to $60 \%$, but regimens that could lead to full resolution would be desirable ${ }^{88,89}$. Oxfendazole, a broad spectrum antihelminthic drug that is widely used in veterinary medicine and is highly effective at clearing T. solium cysts in pigs. It was found to be well tolerated in healthy human volunteers ${ }^{105}$ but is yet to be tested in people with T. solium infection.

Another compelling issue relates to the calcific residues that result from involution of parenchymal cysticerci. As highlighted above, these residues are important epileptogenic substrates in the natural history of cerebral parenchymal cysticercosis and underlie the recurrence of seizures in the long term. Pharmacological interventions that reduce the likelihood of evolution to calcific residues could be beneficial, but no such agents yet exist.

Numerous potential options for cysticercosis control or elimination are available, but the suitability of many these of these measures remains to be explored. Historically, inclusive socioeconomic development led to the elimination of T. solium from Europe ${ }^{106}$, but how soon this goal can be accomplished in LMICs remains an important question.

\section{[H1] Onchocerciasis}

\section{[H2] Epidemiology}


The parasitic disorder onchocerciasis is caused by the nematode, O. volvulus, which is transmitted by blackflies of the genus Simulium. Current estimates suggest that over 14 million individuals are infected with this parasite and up to 198 million people are at risk of infection $^{107}$. Onchocerciasis remains endemic in parts of SSA but its presence seems to be dwindling in some areas of South America and Yemen (FIG. 1) ${ }^{9,108}$. Living in the proximity of rivers, where blackflies breed (FIG. 4), is the leading risk factor for onchocerciasis ${ }^{9}$. Men are more often exposed than women as they tend to spend more time outdoors. For the same reason, children and adolescents are often affected but very young children are spared.

An association between onchocerciasis and epilepsy has long been speculated but has only been reinforced in the past few years by epidemiological observations of a high prevalence of epilepsy in onchocerciasis hotspots in many African countries ${ }^{109-114}$. Some studies, however, contest the association ${ }^{115}$.

Demonstrating causality between onchocerciasis and epilepsy is challenging. Elevated risks of epilepsy with proximity to rivers and high densities of $O$. volvulus microfilariae in skin snips lend support to the causal nature of the association ${ }^{111}$. People in endemic regions in Africa are also exposed to other risk factors for epilepsy, most notably, neurocysticercosis and perinatal insults ${ }^{116-118}$. Ultimately, the proof of causality lies in demonstrating that the parasitic infection predates epilepsy. Observations on the incidence of new-onset epilepsy in a population-based cohort with established onchocercal skin disease seem to support a causal association $^{119}$. Additional studies in population-based samples of new-onset epilepsy from other geographical regions would be advisable.

The latest iteration of the Global Burden of Disease project attributes 719,000 DALYs per year to onchocerciasis, most of which are attributable to skin disease and the remainder to visual impairment ${ }^{3}$. To date, epilepsy has not been taken in to account when calculating the disability burden associated with onchocerciasis ${ }^{107}$. 


\section{[H2] Clinical manifestations}

The cardinal manifestations of onchocerciasis comprise widespread itching owing to skin invasion, and visual impairment with eventual loss of vision ${ }^{107}$. A range of epilepsies have been linked with $O$. volvulus infestation, but two conditions, nodding syndrome and Nagalanka syndrome, have received particular attention ${ }^{120-123}$. The term, nodding syndrome refers to the occurrence of myoclonic, generalized tonic-clonic and absence seizures in addition to frequent 'nodding' episodes in previously healthy children. Nagalanka syndrome shares some features of nodding syndrome but is characterized by growth arrest and malnutrition alongside the seizures. The label onchocerciasis-associated epilepsies (OAE) is given to epilepsies with onset between 3 and 18 years of age in previously healthy individuals with no other recognized risk factors for epilepsy, other than familial clustering and residence in an O. volvulus-endemic region ${ }^{124-126}$. These criteria are widely used in African endemic regions but still require appropriate clinical validation.

\section{[H2] Pathophysiology}

Innate (mainly $\mathrm{T}_{\mathrm{H}} 2$ ) and adaptive $\left(\mathrm{T}_{\mathrm{H}} 1\right)$ immune responses seem to be operational in onchocerciasis, as indicated by the expression of various immune effector molecules in the skin and eyes of affected individuals ${ }^{127}$. Little is known about the pathogenicity of $O$. volvulus in the brain; however, an endosymbiont bacterium, Wolbachia, is co-transmitted with this parasite and is thought to be involved in its pathogenicity ${ }^{128}$

O. volvulus has eluded identification in the brain and cerebrospinal fluid ${ }^{129}$, but in a study published in 2017, anti-leiomodin-1 antibodies were detected using protein array technology in serum and cerebrospinal fluid of people with nodding syndrome ${ }^{130}$. These antibodies cross-react with O. volvulus tropomysin protein and are neurotoxic in mouse 
brains. These preliminary data imply an autoimmune basis for nodding syndrome and perhaps OAE. If the findings can be replicated, they open up the possibility of immunemediated therapies for onchocerciasis.

Ambiguity stems from a paucity of pathological or imaging evidence for an underlying epileptogenic substrate associated with onchocerciasis. Novel evidence accrued through imaging and post-mortem studies in individuals with nodding syndrome admitted to tertiary care in Nigeria suggests subtle remnants of past inflammation but an absence of focal pathological lesions in the cerebral cortex ${ }^{131}$. Instead, imaging indicates diffuse cerebral and cerebellar cortical atrophy, perhaps consistent with symptomatic generalized epilepsy ${ }^{132}$. More pathological and imaging studies from different locations would be desirable to explore further the pathophysiological link between onchocerciasis and epilepsy.

\section{[H2] Treatment and prevention}

Over the years, laudable efforts have been made to control and eliminate onchocerciasis in Africa. Launched in 1974 in West Africa, the Onchocerciasis Control Programme (OCP) relied on extensive insecticide spraying in an effort to control the vector ${ }^{133}$. A highly effective microfilariacidal drug, ivermectin, was identified at Merck in the $1980 \mathrm{~s}^{134}$. Soon after, the company pledged to supply the drug cost-free for as long as necessary to eliminate onchocerciasis $^{135}$. The African Programme for Onchocerciasis Control (APOC) was established in 1995 and eventually took over from the OCP ${ }^{136}$. The APOC expanded coverage to many other African countries and changed the approach from environmental spraying for vector control to wide-ranging community-directed treatment with ivermectin at periodic intervals (TABLE 3). In turn, the APOC was replaced by the inclusive WHOsupported Expanded Special Project for Elimination of Neglected Tropical Diseases (ESPEN) in 2016 $6^{137}$. Collectively, these three programmes have resulted in an impressive 
reduction in onchocerciasis-linked disease burden from an annual DALY rate of over one billion in 1990 to 719,000 in $2016^{138,139}$. The unrestricted availability of ivermectin, international advocacy and favourable governmental responses contributed to infection control in many regions of the 28 African countries that adopted these programmes. Substantial pockets of endemicity remain, however, mainly in conflict areas. WHO is aiming for complete eradication by 2025, but some consider this target to be unrealistic ${ }^{137}$.

\section{[H1] Toxocariasis}

Human toxocariasis is caused by exposure to Toxocara spp. nematodes, which live in the digestive tracts of dogs and cats ${ }^{140}$. The ingested eggs develop into early larvae, which then penetrate the human gut wall to be distributed to many organs including the eyes and brain. Four clinical forms of human toxocariasis are known: visceral larvae migrans, ocular toxocariasis, covert toxocariasis and neural toxocariasis ${ }^{141}$. Various neurological manifestations including acute meningoencephalitis, acute encephalomyelitis, cerebral vasculitis and seizures, have been observed in rare cases.

Exposure to Toxocara is common in many parts of the world, as domesticated dogs and cats are commonplace. Case--control studies from different parts of the world, including the USA, Bolivia, Italy and multiple locations in SSA, have reported small but positive associations between seropositive status for Toxocara spp. and epilepsy ${ }^{142-145}$. Conversely, studies from India, Turkey, Iran, Egypt, and Tanzania were equivocal for the link between Toxocara and epilepsy ${ }^{146-150}$. A meta-analysis published in 2018 confirmed an association, with a pooled odds ratio of 1.69 (95\% CI 1.42-2.01) $)^{151}$.

Whether the association between Toxocara exposure and epilepsy is causal remains to be established. This issue might be resolved by the use of serological studies in incident populations of epilepsy, in which seropositivity would signify antecedent exposure to the 
parasite as opposed to exposure to Toxocara eggs during seizure-related falls, for example. The elucidation of putative epileptogenic substrates in imaging and pathological studies of neural toxocaraiasis and the development of an experimental model of neural invasion would be useful in corroborating causality.

\section{[H1] Other parasitic disorders}

Little is known about the risk of epilepsy associated with infestation with other neurotropic parasites, such as Schistosoma spp., Paragonimus spp., Trypanosoma spp., Echinococcus granulosus and Toxoplasma gondii. Each of these parasites is restricted to specific regions of the world, where prevailing ecological and social factors are conducive to their transmission.

The trematode Schistosoma, of which many species are recognized, causes schistosomiasis, a condition that affects nearly 200 million people, mostly in $\mathrm{SSA}^{152}$. CNS involvement is common but mostly asymptomatic ${ }^{153}$. The flatworm, Paragonimus westermani is the leading species responsible for causing human paragonimiasis ${ }^{154}$. Pulmonary involvement is common in this condition, but cerebral involvement, which can lead to seizures, is rare. The protozoan Trypanosoma brucei gambiense is responsible for human African trypansomiasis (also known as sleeping sickness), which is endemic in over 35 countries in SSA where the vector, the tsetse fly, breeds abundantly ${ }^{155}$. Neurological involvement is thought to be common but has not been accurately quantified ${ }^{156}$. Another cestode, Echinococcus granulosus, is endemic in many countries and regions ${ }^{157}$. Visceral organ involvement is common, whereas cerebral involvement is rare but distinctive enough to be easily recognized on imaging studies.

With the exception of $T$. gondii, the association between exposure to these parasites and the development of epilepsy has not been systematically studied in population-based samples or sufficiently investigated in experimental and clinical settings. Another issue that 
warrants investigation is the high burden of certain parasitic infections, including T. gondii and Trypansoma spp., in HIV-infected individuals and its impact on epilepsy in SSA ${ }^{158}$.

\section{[H1] Conclusions and future prospects}

Effective treatments are in place for the parasitic disorders that we have discussed in this Review, but the impact of these treatments on the development of epilepsy in the long term has not been sufficiently assessed. Novel therapeutic agents are also needed to mitigate brain damage and prevent the development of epilepsy by halting epileptogenesis. Potential approaches include the identification of molecular targets involved in cytoadherence in cerebral malaria or the inflammatory cascade in neurocysticercosis and onchocerciasis. In the interim, primary prevention — that is, controlling, eliminating and eradicating parasitic disorders linked to epilepsy — remains the only available approach to reduce the epilepsy burden.

Linking epilepsy care programmes to parasite control programmes in LMICs is appropriate and feasible. Such an approach should engender the interest of policy makers and public alike, thereby increasing attention to otherwise little-known parasitic disorders. Firm policies and recommendations for control should be developed and adopted by governments in LMICs. Disease-specific guidelines for control and treatment should also be promptly followed by concerned institutions and agencies. Important components from an implementation perspective include mapping of parasitic disorders within each country and region, development of a firm and feasible action plan. Effective monitoring of control programmes through appropriate surveillance tools, and evaluation of outcomes and impact are essential ${ }^{159}$. Another crucial step in the process is to chart out all the available epidemiological information on the parasite and correlate it with epilepsy indices. 
The development of parasite control measures in an effort to reduce the epilepsy burden is challenging in several respects (FIGS 2-4). Secondary prevention of epilepsies after onset of brain infection remains an elusive goal. The considerable time lag between the start of the parasitic infection and the occurrence of late unprovoked seizures makes it difficult to appreciate the association between infection and epilepsy. In addition, many of the parasites occur in geographically restricted regions of the world. Stand-alone programmes for locally prevalent parasitoses in these regions are unlikely to be logistically viable, and instead need to be integrated in community and primary care initiatives. Some of the affected areas are inaccessible or blighted by war and political conflict. Approaches to parasite control are also thwarted by vector and agent resistance, poor acceptance by communities and implementation problems. No single control strategy is likely to be effective, and a combination of approaches will be required, which becomes operationally difficult.

The One Health approach recognizes the roles of humans, animals and the environment in the perpetuation of zoonoses ${ }^{159}$. This initiative is a call to medics, veterinarians and ecologists, as well as experts from other sectors and disciplines, to collaborate to monitor and control zoonotic parasites. Preliminary evidence suggests that integration of human, animal and environmental health is feasible and can be instrumental in disease control. Community empowerment through effective risk communication, animal and human treatment, environmental interventions, food safety, and water, sanitation and hygiene (WASH) form the core principles for control, elimination and eradication of zoonotic and vector-borne parasites. Parasite elimination could be the key to epilepsy prevention in LMICs and should be integrated within the existing disease control activities of local health systems.

\section{References}


1. World Health Organization. Fact sheet: Epilepsy. WHO, https://www.who.int/newsroom/fact-sheets/detail/epilepsy (2019).

2. GBD 2017 Causes of Death Collaborators. Global, regional, and national age-sexspecific mortality for 282 causes of death in 195 countries and territories, 1980-2017: a systematic analysis for the Global Burden of Disease Study 2017. Lancet 392, 17361788 (2018).

3. GBD 2017 Disease and Injury Incidence and Prevalence Collaborators. Global, regional, and national incidence, prevalence, and years lived with disability for 354 diseases and injuries for 195 countries and territories, 1990-2017: a systematic analysis for the Global Burden of Disease Study 2017. Lancet 392, 1789-1858 (2018).

4. Thurman, D. J. et al. The primary prevention of epilepsy: a report of the Prevention Task Force of the International League Against Epilepsy. Epilepsia 59, 905-914 (2018).

5. World Health Organization. Global burden of epilepsy and the need for coordinated action at the country level to address its health, social and public knowledge implications: draft resolution proposed by Maldives, People’s Republic of China and Russian Federation. WHO, https://apps.who.int/iris/handle/10665/251859 (2015).

6. Torgerson, P. R. \& Macpherson, C. N.. The socioeconomic burden of parasitic zoonoses: global trends. Vet. Parasitol. 182, 79-95 (2011).

7. Karesh, W. B. et al. Ecology of zoonoses: natural and unnatural histories. Lancet 380, 1936-1945 (2012).

8. Fiest, K. M. et al. Prevalence and incidence of epilepsy: a systematic review and metaanalysis of international studies. Neurology 88, 296-303 (2017).

9. Colebunders, R. et al. From river blindness to river epilepsy: implications for onchocerciasis elimination programmes. PLoS Negl. Trop. Dis. 13, e0007407 (2019). 
10. Raghava, M. V. et al. Detecting spatial clusters of Taenia solium infections in a rural block in South India. Trans. R. Soc. Trop. Med. Hyg. 104, 601-612 (2010).

11. Newton, C. R., Hien, T. T. \& White, N. Cerebral malaria. J. Neurol. Neurosurg. Psychiatry 69, 433-441 (2000).

12. Carpio, A., Fleury, A. \& Hauser, W. A. Neurocysticercosis: five new things. Neurol. Clin. Pract. 3, 118-125 (2013).

13. Carabin, $\mathrm{H}$. et al. Clinical manifestations associated with neurocysticercosis: a systematic review. PLoS Negl. Trop. Dis. 5, e1152 (2011).

14. Beghi, E. et al. Recommendation for a definition of acute symptomatic seizure. Epilepsia 51, 671-675 (2010).

15. Fisher, R. S. et al. ILAE official report: a practical clinical definition of epilepsy. Epilepsia 55, 475-482 (2014).

16. Singh, G., Burneo, J. G. \& Sander, J. W. From seizures to epilepsy and its substrates: neurocysticercosis. Epilepsia 54, 783-792 (2013).

17. Vezzani, A., French, J., Bartfai, T. \& Baram, T. Z. The role of inflammation in epilepsy. Nat. Rev. Neurol. 7, 31-40 (2011).

18. Terrone, G., Salamone, A. \& Vezzani, A. Inflammation and epilepsy: preclinical findings and potential clinical translation. Curr. Pharm. Des. 23, 5569-5576 (2017).

19. Frigerio, F. et al. Neuroinflammation alters integrative properties of rat hippocampal pyramidal cells. Mol. Neurobiol. 55, 7500-7511 (2018).

20. Kostoula, C. et al. TLR3 preconditioning induces anti-inflammatory and anti-ictogenic effects in mice mediated by the IRF3/IFN- $\beta$ axis. Brain. Behav. Immun. 81, 598-607 (2019).

21. Dickstein, L. P. et al. Neuroinflammation in neocortical epilepsy measured by PET imaging of translocator protein. Epilepsia 60, 1248-1254 (2019). 
22. van Vliet, E. A., Aronica, E., Vezzani, A. \& Ravizza, T. Review: Neuroinflammatory pathways as treatment targets and biomarker candidates in epilepsy: emerging evidence from preclinical and clinical studies. Neuropathol. Appl. Neurobiol. 44, 91-111 (2018).

23. Nash, T. E. et al. Neurocysticercosis: a natural human model of epileptogenesis. Epilepsia 56, 177-183 (2015).

24. Nájera, J. A., González-Silva, M. \& Alonso, P. L. Some lessons for the future from the Global Malaria Eradication Programme (1955-1969). PLoS Med 8, e1000412 (2011).

25. World Health Organization. World Malaria Report 2010. WHO, https://www.who.int/malaria/world_malaria_report_2010/worldmalariareport2010.pdf (2010).

26. Battle, K. E. et al. Mapping the global endemicity and clinical burden of Plasmodium vivax, 2000-17: a spatial and temporal modelling study. Lancet 394, 332-343 (2019).

27. Weiss, D. J. et al. Mapping the global prevalence, incidence, and mortality of Plasmodium falciparum, 2000-17: a spatial and temporal modelling study. Lancet 394, 322-331 (2019).

28. Wiebe, A. et al. Geographical distributions of African malaria vector sibling species and evidence for insecticide resistance. Malar. J. 16, 85 (2017).

29. Cohen, J. M. et al. Malaria resurgence: a systematic review and assessment of its causes. Malar. J. 11, 122 (2012).

30. Idro, R., Jenkins, N. E. \& Newton, C. R. Pathogenesis, clinical features, and neurological outcome of cerebral malaria. Lancet Neurol, 4, 827-840 (2005).

31. Crawley, J. et al. Seizures and status epilepticus in childhood cerebral malaria. QJM 89, 591-598 (1996).

32. Warrell, D. A. Cerebral malaria: clinical features, pathophysiology and treatment. Ann. Trop. Med. Parasitol. 91, 875-884 (1997) 
33. Dondorp, A. M. et al. The relationship between age and the manifestations of and mortality associated with severe malaria. Clin. Infect. Dis. 47, 151-157 (2008).

34. Dokunmu, T. M. et al. Asymptomatic malaria infections and Pfmdr1 mutations in an endemic area of Nigeria. Malar. J. 18, 218 (2019).

35. Taylor, T. E. et al. Differentiating the pathologies of cerebral malaria by postmortem parasite counts. Nat. Med. 10, 143-145 (2004).

36. Birbeck, G. L. et al. Blantyre Malaria Project Epilepsy Study (BMPES) of neurological outcomes in retinopathy-positive paediatric cerebral malaria survivors: a prospective cohort study. Lancet Neurol. 9, 1173-1181 (2010).

37. Birbeck, G. L. et al. Identification of malaria retinopathy improves the specificity of the clinical diagnosis of cerebral malaria: findings from a prospective cohort study. Am. J. Trop. Med. Hyg. 82, 231-234 (2010).

38. Kochar, D. K. et al. Cerebral malaria in Indian adults: a prospective study of 441 patients from Bikaner, north-west India. J. Assoc. Physicians India 50, 234-241 (2002).

39. Artemether-Quinine Meta-analysis Study Group. A meta-analysis using individual patient data of trials comparing artemether with quinine in the treatment of severe falciparum malaria. Trans. R. Soc. Trop. Med. Hyg. 95, 637-650 (2001).

40. Idro, R., Carter, J. A., Fegan, G., Neville, B. G. \& Newton, C. R. Risk factors for persisting neurological and cognitive impairments following cerebral malaria. Arch. Dis. Child. 91, 142-148 (2006).

41. Christensen, S. S. \& Eslick, G. D. Cerebral malaria as a risk factor for the development of epilepsy and other long-term neurological conditions: a meta-analysis. Trans. R. Soc. Trop. Med. Hyg. 109, 233-238 (2015). 
42. Opoka, R. O., Bangirana, P., Boivin, M. J., John, C. C. \& Byarugaba, J. Seizure activity and neurological sequelae in Ugandan children who have survived an episode of cerebral malaria. Afr. Health Sci. 9, 75-81 (2009).

43. Ngoungou, E. B. et al. Cerebral malaria and sequelar epilepsy: first matched casecontrol study in Gabon. Epilepsia 47, 2147-2153 (2006).

44. Ngoungou, E. B. et al. Epilepsy as a consequence of cerebral malaria in area in which malaria is endemic in Mali, West Africa. Epilepsia 47, 873-879 (2006).

45. Carter, J. A. et al. Developmental impairments following severe falciparum malaria in children. Trop. Med. Int. Health 10, 3-10 (2005).

46. Postels, D. G. et al. Neurologic outcomes in retinopathy-negative cerebral malaria survivors. Neurology 79, 1268-1272 (2012).

47. de Oca, M. M., Engwerda, C. \& Haque, A. Plasmodium berghei ANKA (PbA) infection of C57BL/6J mice: a model of severe malaria. Methods Mol. Biol. 1031, 203-213 (2013).

48. Storm, J. et al. Cerebral malaria is associated with differential cytoadherence to brain endothelial cells. EMBO Mol. Med. 11, (2019).

49. Storm, J. \& Craig, A. G. Pathogenesis of cerebral malaria — inflammation and cytoadherence. Front. Cell. Infect. Microbiol. 4, 100 (2014).

50. Jensen, A. R., Adams, Y. \& Hviid, L. Cerebral Plasmodium falciparum malaria: the role of PfEMP1 in its pathogenesis and immunity, and PfEMP1-based vaccines to prevent it. Immunol. Rev. 293, 230-252 (2020).

51. O’Regan, N. et al. A novel role for von Willebrand factor in the pathogenesis of experimental cerebral malaria. Blood 127, 1192-1201 (2016). 
52. Cruz, L. N., Wu, Y., Ulrich, H., Craig, A. G. \& Garcia, C. R. Tumor necrosis factor reduces Plasmodium falciparum growth and activates calcium signaling in human malaria parasites. Biochim. Biophys. Acta 1860, 1489-1497 (2016).

53. Conroy, A. L. et al. Angiopoietin-2 levels are associated with retinopathy and predict mortality in Malawian children with cerebral malaria: a retrospective case-control study*. Crit. Care Med. 40, 952-959 (2012).

54. Shabani, E. et al. Elevated cerebrospinal fluid tumour necrosis factor is associated with acute and long-term neurocognitive impairment in cerebral malaria. Parasite Immunol. https://doi.org/10.1111/pim.12438 (2017).

55. Crawley, J. et al. Effect of phenobarbital on seizure frequency and mortality in childhood cerebral malaria: a randomised, controlled intervention study. Lancet 355, 701-706 (2000).

56. White, N. J., Looareesuwan, S., Phillips, R. E., Chanthavanich, P. \& Warrell, D. A. Single dose phenobarbitone prevents convulsions in cerebral malaria. Lancet 2, 64-66 (1988).

57. Birbeck, G. L. et al. A clinical trial of enteral levetiracetam for acute seizures in pediatric cerebral malaria. BMC Pediatr. 19, 399 (2019).

58. Gwer, S. A. et al. Fosphenytoin for seizure prevention in childhood coma in Africa: a randomized clinical trial. J. Crit. Care 28, 1086-1092 (2013).

59. Eisele, T. P., Keating, J., Littrell, M., Larsen, D. \& Macintyre, K. Assessment of insecticide-treated bednet use among children and pregnant women across 15 countries using standardized national surveys. Am. J. Trop. Med. Hyg. 80, 209-214 (2009).

60. Katureebe, A. et al. Measures of malaria burden after long-lasting insecticidal net distribution and indoor residual spraying at three sites in Uganda: a prospective observational study. PLoS Med. 13, e1002167 (2016). 
61. Lengeler, C. Insecticide-treated nets for preventing malaria. Cochrane Database Syst. Rev. 11, CD000363 (2018).

62. West, P. A. et al. Enhanced protection against malaria by indoor residual spraying in addition to insecticide treated nets: is it dependent on transmission intensity or net usage. PLoS One 10, e0115661 (2015).

63. Westercamp, N. \& Arguin, P. M. Malaria chemoprophylaxis: a proven public health intervention for international travelers. Travel Med. Infect. Dis. 13, 8-9 (2015).

64. Bhatt, S. et al. The effect of malaria control on Plasmodium falciparum in Africa between 2000 and 2015. Nature 526, 207-211 (2015).

65. Potchen, M. J. et al. Acute brain MRI findings in 120 Malawian children with cerebral malaria: new insights into an ancient disease. AJNR Am. J. Neuroradiol. 33, 1740-1746 (2012).

66. Postels, D. G. et al. Brain MRI of children with retinopathy-negative cerebral malaria. Am. J. Trop. Med. Hyg. 91, 943-949 (2014).

67. Mohanty, S. et al. Magnetic resonance imaging of cerebral malaria patients reveals distinct pathogenetic processes in different parts of the brain. mSphere 2, e00193-17 (2017).

68. Frölich, A. M. et al. Brain magnetic resonance imaging in imported malaria. Malar. J. 18, 74 (2019).

69. García, H. H., Gonzalez, A. E., Evans, C. A., Gilman, R. H. \& Cysticercosis Working Group in Peru. Taenia solium cysticercosis. Lancet 362, 547-556 (2003).

70. World Health Organization WHO estimates of the global burden of foodborne diseases. WHO, https://apps.who.int/iris/bitstream/handle/10665/199350/9789241565165_eng.pdf?sequ ence $=1$ (2015). 
71. Carpio, A., Placencia, M., Santillán, F. \& Escobar, A. A proposal for classification of neurocysticercosis. Can. J. Neurol. Sci. 21, 43-47 (1994).

72. Singh, G. et al. Association between epilepsy and cysticercosis and toxocariasis: a population-based case-control study in a slum in India. Epilepsia 53, 2203-2208 (2012).

73. Montano, S. M. et al. Neurocysticercosis: association between seizures, serology, and brain CT in rural Peru. Neurology 65, 229-233 (2005).

74. Rajshekhar, V., Raghava, M. V., Prabhakaran, V., Oommen, A. \& Muliyil, J. Active epilepsy as an index of burden of neurocysticercosis in Vellore district, India. Neurology 67, 2135-2139 (2006).

75. Nsengiyumva, G. et al. Cysticercosis as a major risk factor for epilepsy in Burundi, east Africa. Epilepsia 44, 950-955 (2003).

76. Garcia, H. H., Rodriguez, S., Friedland, J. S. \& Cysticercosis Working Group in Peru. Immunology of Taenia solium taeniasis and human cysticercosis. Parasite Immunol. 36, 388-396 (2014).

77. Fleury, A., Cardenas, G., Adalid-Peralta, L., Fragoso, G. \& Sciutto, E. Immunopathology in Taenia solium neurocysticercosis. Parasite Immunol. 38, 147-157 (2016).

78. Chavarría, A. et al. TH2 profile in asymptomatic Taenia solium human neurocysticercosis. Microbes Infect. 5, 1109-1115 (2003).

79. Robinson, P., Atmar, R. L., Lewis, D. E. \& White, A. C. Granuloma cytokines in murine cysticercosis. Infect. Immun. 65, 2925-2931 (1997).

80. Stringer, J. L., Marks, L. M., White, A. C. \& Robinson, P. Epileptogenic activity of granulomas associated with murine cysticercosis. Exp. Neurol. 183, 532-536 (2003). 
81. Verma, A. et al. Toll-like receptor 4 polymorphism and its association with symptomatic neurocysticercosis. J. Infect. Dis. 202, 1219-1225 (2010).

82. Verma, A. et al. Association of MMP-2 and MMP-9 with clinical outcome of neurocysticercosis. Parasitology 138, 1423-1428 (2011).

83. Nash, T. E. et al. Calcific neurocysticercosis and epileptogenesis. Neurology 62, 19341938 (2004).

84. Nash, T. E. et al. Perilesional brain oedema and seizure activity in patients with calcified neurocysticercosis: a prospective cohort and nested case-control study. Lancet Neurol. 7, 1099-1105 (2008).

85. Chawla, S. et al. Demonstration of scolex in calcified cysticercus lesion using gradient echo with or without corrected phase imaging and its clinical implications. Clin. Radiol. 57, 826-834 (2002).

86. Gupta, R. K., Kumar, R., Chawla, S. \& Pradhan, S. Demonstration of scolex within calcified cysticercus cyst: its possible role in the pathogenesis of perilesional edema. Epilepsia 43, 1502-1508 (2002).

87. White, A. C. et al. Diagnosis and Treatment of Neurocysticercosis: 2017 Clinical Practice Guidelines by the Infectious Diseases Society of America (IDSA) and the American Society of Tropical Medicine and Hygiene (ASTMH). Am. J. Trop. Med. Hyg. 98, 945-966 (2018).

88. Garcia, H. H. et al. Efficacy of combined antiparasitic therapy with praziquantel and albendazole for neurocysticercosis: a double-blind, randomised controlled trial. Lancet Infect. Dis. 14, 687-695 (2014).

89. Garcia, H. H. et al. A trial of antiparasitic treatment to reduce the rate of seizures due to cerebral cysticercosis. N. Engl. J. Med. 350, 249-258 (2004). 
90. Carpio, A. et al. Effects of albendazole treatment on neurocysticercosis: a randomised controlled trial. J. Neurol. Neurosurg. Psychiatry 79, 1050-1055 (2008).

91. Nash, T. E., Pretell, J. \& Garcia, H. H. Calcified cysticerci provoke perilesional edema and seizures. Clin. Infect. Dis. 33, 1649-1653 (2001).

92. Carpio, A. et al. Exploring the complex associations over time among albendazole treatment, cyst evolution, and seizure outcomes in neurocysticercosis. Epilepsia 60, 1820-1828 (2019).

93. Otte, W. M., Singla, M., Sander, J. W. \& Singh, G. Drug therapy for solitary cysticercus granuloma: a systematic review and meta-analysis. Neurology $\mathbf{8 0}$, 152-162 (2013).

94. Zhao, B. C. et al. Albendazole and corticosteroids for the treatment of solitary cysticercus granuloma: a network meta-analysis. PLoS Negl. Trop. Dis. 10, e0004418 (2016).

95. The Carter Center. Summary of the Twenty-First Meeting of the International Task Force for Disease Eradication (II) July 10, 2013. The Carter Center, https://www.cartercenter.org/resources/pdfs/news/health_publications/itfde/itfdesummary-071013.pdf (2013).

96. World Health Organization. Progress on drinking water and sanitation: 2015 update and MDG assessment. WHO, https://www.who.int/water_sanitation_health/publications/jmp-2015-update/en/ (2015)

97. United Nations. Sustainable development goals. United Nations, https://sustainabledevelopment.un.org/?menu=1300 (2015)

98. Garn, J. V. et al. The impact of sanitation interventions on latrine coverage and latrine use: a systematic review and meta-analysis. Int. J. Hyg. Environ. Health 220, 329-340 (2017). 
99. Orgill-Meyer, J. et al. Long-term impact of a community-led sanitation campaign in India, 2005-2016. Bull. World Health Organ. 97, 523-533A (2019).

100. Gilman, R. H. et al. Prevention and control of Taenia solium taeniasis/cysticercosis in Peru. Pathog. Glob. Health 106, 312-318 (2012).

101. Garcia, H. H., O’Neal, S. E., Gilman, R. H. \& Cysticercosis Working Group in Peru. Elimination of Taenia solium transmission in Peru. N. Engl. J. Med. 375, 1196-1197 (2016).

102. Sarti, E. et al. Development and evaluation of a health education intervention against Taenia solium in a rural community in Mexico. Am. J. Trop. Med. Hyg. 56, 127-132 (1997).

103. Hobbs, E. C. et al. Preliminary assessment of the computer-based Taenia solium educational program ‘The Vicious Worm’ on knowledge uptake in primary school students in rural areas in eastern Zambia. Trop. Med. Int. Health 23, 306-314 (2018).

104. Hobbs, E. C. et al. Effects of ‘The Vicious Worm’ educational tool on Taenia solium knowledge retention in Zambian primary school students after one year. PLoS Negl. Trop. Dis. 13, e0007336 (2019).

105. An, G. et al. Pharmacokinetics, safety, and tolerability of oxfendazole in healthy volunteers: a randomized, placebo-controlled first-in-human single-dose escalation study. Antimicrob. Agents Chemother. 63, e02255-18 (2019).

106. Del Brutto, O. H. \& García, H. H. Taenia solium cysticercosis - the lessons of history. J. Neurol. Sci. 359, 392-395 (2015).

107. Murdoch, M. E. Onchodermatitis: where are we now. Trop. Med. Infect. Dis. 3, E94 (2018). 
108. Colebunders, R., Stolk, W. A., Siewe Fodjo, J. N., Mackenzie, C. D. \& Hopkins, A. Elimination of onchocerciasis in Africa by 2025: an ambitious target requires ambitious interventions. Infect. Dis. Poverty 8, 83 (2019).

109. Mukendi, D. et al. High prevalence of epilepsy in an onchocerciasis endemic health zone in the Democratic Republic of the Congo, despite 14 years of community-directed treatment with ivermectin: a mixed-method assessment. Int. J. Infect. Dis. 79, 187-194 (2019).

110. Mmbando, B. P. et al. High prevalence of epilepsy in two rural onchocerciasis endemic villages in the Mahenge area, Tanzania, after 20 years of community directed treatment with ivermectin. Infect. Dis. Poverty 7, 64 (2018).

111. Mandro, M. et al. Onchocerca volvulus as a risk factor for developing epilepsy in onchocerciasis endemic regions in the Democratic Republic of Congo: a case control study. Infect. Dis. Poverty 7, 79 (2018).

112. Colebunders, R. et al. Prevalence of river epilepsy in the Orientale Province in the Democratic Republic of the Congo. PLoS Negl. Trop. Dis. 10, e0004478 (2016).

113. Colebunders, R. et al. Risk factors for epilepsy in Bas-Uélé Province, Democratic Republic of the Congo: a case-control study. Int. J. Infect. Dis. 49, 1-8 (2016).

114. Colebunders, R. et al. High prevalence of onchocerciasis-associated epilepsy in villages in Maridi County, Republic of South Sudan: a community-based survey. Seizure 63, 93101 (2018).

115. Konig, R., Nanri, A., Meindl, M. \& Matuja, W. The role of Onchocerca volvulus in the development of epilepsy in a rural area of Tanzania. Parasitology 137, 1559-1568 (2010). 
116. Winkler, A. S. Neurocysticercosis in sub-Saharan Africa: a review of prevalence, clinical characteristics, diagnosis, and management. Pathog. Glob. Health 106, 261-274 (2012).

117. Akombi, B. J. \& Renzaho, A. M. Perinatal mortality in Sub-Saharan Africa: A metaanalysis of demographic and health surveys. Ann. Glob. Health 85, 106 (2019).

118. Kamuyu, G. et al. Exposure to multiple parasites is associated with the prevalence of active convulsive epilepsy in sub-Saharan Africa. PLoS Negl. Trop. Dis. 8, e2908 (2014).

119. Chesnais, C. B. et al. The temporal relationship between onchocerciasis and epilepsy: a population-based cohort study. Lancet Infect. Dis. 18, 1278-1286 (2018).

120. Mwaka, A. D., Semakula, J. R., Abbo, C. \& Idro, R. Nodding syndrome: recent insights into etiology, pathophysiology, and treatment. Res. Rep. Trop. Med. 9, 89-93 (2018).

121. Foltz, J. L. et al. An epidemiologic investigation of potential risk factors for nodding syndrome in Kitgum District, Uganda. PLoS One 8, e66419 (2013).

122. Föger, K. et al. Nakalanga syndrome: clinical characteristics, potential causes, and its relationship with recently described nodding syndrome. PLoS Negl. Trop. Dis. 11, e0005201 (2017)

123. Sejvar, J. J. et al. Clinical, neurological, and electrophysiological features of nodding syndrome in Kitgum, Uganda: an observational case series. Lancet Neurol. 12, 166-174 (2013).

124. Siewe, J. F. N. et al. Clinical presentations of onchocerciasis-associated epilepsy (OAE) in Cameroon. Epilepsy Behav. 90, 70-78 (2019).

125. Colebunders, R. et al. Clinical characteristics of onchocerciasis-associated epilepsy in villages in Maridi County, Republic of South Sudan. Seizure 62, 108-115 (2018). 
126. Colebunders, R., Nelson Siewe, F. J. \& Hotterbeekx, A. Onchocerciasis-associated epilepsy, an additional reason for strengthening onchocerciasis elimination programs. Trends Parasitol. 34, 208-216 (2018).

127. Paganelli, R., Ngu, J. L. \& Levinsky, R. J. Circulating immune complexes in onchocerciasis. Clin. Exp. Immunol. 39, 570-575 (1980).

128. Pearlman, E. \& Gillette-Ferguson, I. Onchocerca volvulus, Wolbachia and river blindness. Chem. Immunol. Allergy 92, 254-265 (2007).

129. Winkler, A. S. et al. MRI findings in people with epilepsy and nodding syndrome in an area endemic for onchocerciasis: an observational study. Afr. Health Sci. 13, 529-540 (2013).

130. Johnson, T. P. et al. Nodding syndrome may be an autoimmune reaction to the parasitic worm Onchocerca volvulus. Sci. Transl. Med. 9, eaaf6953 (2017).

131. Hotterbeekx, A. et al. Neuroinflammation and not tauopathy is a predominant pathological signature of nodding syndrome. J. Neuropathol. Exp. Neurol. 78, 10491058 (2019).

132. Idro, R. et al. Nodding syndrome in Ugandan children — clinical features, brain imaging and complications: a case series. BMJ Open 3, e002540 (2013).

133. Boatin, B. A. The current state of the Onchocerciasis Control Programme in West Africa. Trop. Doct. 33, 209-214 (2003).

134. Campbell, W. C., Fisher, M. H., Stapley, E. O., Albers-Schönberg, G. \& Jacob, T. A. Ivermectin: a potent new antiparasitic agent. Science 221, 823-828 (1983).

135. Omura, S. \& Crump, A. The life and times of ivermectin - a success story. Nat. Rev. Microbiol. 2, 984-989 (2004).

136. Hopkins, A. D. Neglected tropical diseases in Africa: a new paradigm. Int. Health 8 (Suppl. 1), i28-i33 (2016). 
137. World Health Organization Regional Office for Africa. Expanded Special Project for Elimination of Neglected Tropical Disease. WHO, https://www.afro.who.int/healthtopics/expanded-special-project-elimination-neglected-tropical-disease (2019).

138. Murray, C. J. L. \& Lopez, A. D. The Global Burden of Disease : a Comprehensive Assessment of Mortality and Disability From Diseases, Injuries, and Risk Factors in 1990 and Projected to 2020 (WHO, Geneva, 1996).

139. Boullé, C. et al. Impact of 19 years of mass drug administration with ivermectin on epilepsy burden in a hyperendemic onchocerciasis area in Cameroon. Parasit. Vectors 12, 114 (2019).

140. Rubinsky-Elefant, G., Hirata, C. E., Yamamoto, J. H. \& Ferreira, M. U. Human toxocariasis: diagnosis, worldwide seroprevalences and clinical expression of the systemic and ocular forms. Ann. Trop. Med. Parasitol. 104, 3-23 (2010).

141. Nicoletti, A. Toxocariasis. Handb. Clin. Neurol. 114, 217-228 (2013).

142. Nicoletti, A. et al. Epilepsy, cysticercosis, and toxocariasis: a population-based casecontrol study in rural Bolivia. Neurology 58, 1256-1261 (2002).

143. Nicoletti, A. et al. Epilepsy and toxocariasis: a case-control study in Burundi. Epilepsia 48, 894-899 (2007).

144. Nicoletti, A. et al. Epilepsy and toxocariasis: a case-control study in Italy. Epilepsia 49, 594-599 (2008).

145. Glickman, L. T., Cypess, R. H., Crumrine, P. K. \& Gitlin, D. A. Toxocara infection and epilepsy in children. J. Pediatr. 94, 75-78 (1979).

146. Allahdin, S., Khademvatan, S., Rafiei, A., Momen, A. \& Rafiei, R. Frequency of Toxoplasma and Toxocara Sp. antibodies in epileptic patients, in South Western Iran. Iran. J. Child. Neurol. 9, 32-40 (2015). 
147. Noormahomed, E. V. et al. A cross-sectional serological study of cysticercosis, schistosomiasis, toxocariasis and echinococcosis in HIV-1 infected people in Beira, Mozambique. PLoS Negl. Trop. Dis. 8, e3121 (2014).

148. Eraky, M. A., Abdel-Hady, S. \& Abdallah, K. F. Seropositivity of Toxoplasma gondii and Toxocara spp. in children with cryptogenic epilepsy, Benha, Egypt. Korean J. Parasitol. 54, 335-338 (2016).

149. Zibaei, M., Firoozeh, F., Bahrami, P. \& Sadjjadi, S. M. Investigation of anti-Toxocara antibodies in epileptic patients and comparison of two methods: ELISA and Western blotting. Epilepsy Res. Treat. 2013, 156815 (2013).

150. Winkler, A. S. et al. Anticysticercal and antitoxocaral antibodies in people with epilepsy in rural Tanzania. Trans. R. Soc. Trop. Med. Hyg. 102, 1032-1038 (2008).

151. Luna, J. et al. Updated evidence of the association between toxocariasis and epilepsy: systematic review and meta-analysis. PLoS Negl. Trop. Dis. 12, e0006665 (2018).

152. King, C. H. \& Galvani, A. P. Underestimation of the global burden of schistosomiasis. Lancet 391, 307-308 (2018).

153. Coyle, C. M. Schistosomiasis of the nervous system. Handb. Clin. Neurol. 114, 271281 (2013).

154. Xia, Y., Ju, Y., Chen, J. \& You, C. Cerebral paragonimiasis: a retrospective analysis of 27 cases. J. Neurosurg. Pediatr. 15, 101-106 (2015).

155. Franco, J. R., Simarro, P. P., Diarra, A. \& Jannin, J. G. Epidemiology of human African trypanosomiasis. Clin. Epidemiol. 6, 257-275 (2014).

156. Kennedy, P. G. E. Update on human African trypanosomiasis (sleeping sickness). J. Neurol. 266, 2334-2337 (2019).

157. Svrckova, P., Nabarro, L., Chiodini, P. L. \& Jäger, H. R. Disseminated cerebral hydatid disease (multiple intracranial echinococcosis). Pract. Neurol. 19, 156-163 (2019). 
158. Wang, Z. D. et al. Prevalence and burden of Toxoplasma gondii infection in HIVinfected people: a systematic review and meta-analysis. Lancet HIV 4, e177-e188 (2017).

159. American Veterinary Medical Association. One Health Initiative Task Force: final report. AVMA, https://www.avma.org/sites/default/files/resources/onehealth_final.pdf (2018).

160. Siewe Fodjo, J. N. et al. Epidemiology of onchocerciasis-associated epilepsy in the Mbam and Sanaga river valleys of Cameroon: impact of more than 13 years of ivermectin. Infect. Dis. Poverty 7, 114 (2018).

161. Patil, P. R., Gemma, S., Campiani, G. \& Craig, A. G. Broad inhibition of Plasmodium falciparum cytoadherence by (+)-epigallocatechin gallate. Malar. J. 10, 348 (2011).

162. WHO Global Health Observatory Data Repository: http://apps.who.int/ghodata/

163. Roser, M. \& Ritchie, H. Malaria. Our World in Data, https://ourworldindata.org/malaria (2019).

164. World Health Organization. Distribution of onchocerciasis, worldwide, 2013. WHO, https://www.who.int/onchocerciasis/distribution/Distribution_onchocerciasis_2013.pdf? $\underline{\text { ua}=1}$ (2014).

165. Centers for Disease Control and Prevention. Malaria. CDC, https://www.cdc.gov/dpdx/malaria/index.html (2019).

166. Garcia, H. H., Del Brutto, O. H. \& Cysticercosis Working in Peru. Neurocysticercosis: updated concepts about an old disease. Lancet Neurol. 4, 653-661 (2005).

167. Colebunders, R. et al. From river blindness control to elimination: bridge over troubled water. Infect Dis Poverty 7, 21 (2018).

168. Centers for Disease Control and Prevention. Onchocerciasis. CDC, https://www.cdc.gov/dpdx/onchocerciasis/index.html (2017). 


\section{Acknowledgements}

This work was carried out at NIHR University College London Hospitals Biomedical Research Centre, which receives a proportion of funding from the UK Department of Health's Research Centres funding scheme. SAA is a Commonwealth Scholar and is funded by the UK Department of International Development. J. W. S. receives research support from the Dr. Marvin Weil Epilepsy Research Fund, from the UK Epilepsy Society and the Christelijke Vereniging voor de Verpleging van Lijders aan Epilepsie, Netherlands.

\section{Author contributions}

The article was conceptualised by G.S. and J.W.S. All authors researched data for the article and reviewed and/or edited the manuscript before submission. G. S. produced the first draft and all others made substantial contributions to discussion of the content.

\section{Competing interests}

J. W. S. has received personal fees from Eisai, UCB and Zogenix and grants from UCB and GW Pharmaceuticals, outside the submitted work. His current position is endowed by the Epilepsy Society. The other authors declare no competing interests.

\section{Peer review information}

Nature Reviews Neurology thanks A. Carpio and other, anonymous, reviewer(s) for their contribution to the peer review of this work.

\section{Publisher's note}


Springer Nature remains neutral with regard to jurisdictional claims in published maps and institutional affiliations.

\section{Related links}

WHO Global Health Observatory Data Repository: http://apps.who.int/ghodata/

\section{Key points}

- The preventable risk factors for epilepsy include CNS infections, among which parasitic disorders constitute an important subgroup.

- Parasitic disorders that have been linked to epilepsy, including cerebral malaria, Taenia solium neurocysticercosis, onchocerciasis and toxocariasis, are especially prevalent in resource-limited settings.

- Effective treatments are in place for many parasitic disorders, but the long-term impact of these treatments on the development of epilepsy has not been assessed.

- Currently, primary prevention — that is, control, elimination and eradication of parasitic disorders — remains the only viable approach to reduce the epilepsy burden associated with these conditions. 
Table 1 Common parasitic diseases linked to epilepsy

\begin{tabular}{|c|c|c|c|}
\hline Characteristic & Cerebral malaria & Taenia solium cysticercosis & Onchocerciasis \\
\hline Agent & Plasmodium falciparum & Taenia solium & Onchocerca volvulus \\
\hline Infective stage & Sporozoites & Ova & L3-stage larvae \\
\hline Vector & Anopheles mosquito & NA & Simulium spp. (blackfly) \\
\hline Primary host & NA & Human & NA \\
\hline Intermediate host & NA & Pig & NA \\
\hline $\begin{array}{l}\text { Ecological factors } \\
\text { responsible for } \\
\text { endemicity }\end{array}$ & $\begin{array}{l}\text { Warm tropical climate, } \\
\text { humidity, stagnant } \\
\text { water, foliage, rainfall }\end{array}$ & $\begin{array}{l}\text { Porcine cysticercosis: open defecation, } \\
\text { free-ranging pigs } \\
\text { Intestinal taeniasis: poor meat hygiene, } \\
\text { consumption of raw/undercooked } \\
\text { infested pork } \\
\text { Human cysticercosis: inadequate } \\
\text { sanitation, poor personal hygiene }\end{array}$ & Proximity to rivers \\
\hline $\begin{array}{l}\text { Human factors } \\
\text { associated with } \\
\text { infection }\end{array}$ & $\begin{array}{l}\text { Skin exposure to } \\
\text { mosquitoes, more in } \\
\text { children }\end{array}$ & Poor hygiene & $\begin{array}{l}\text { Skin exposure to blackfly } \\
\text { (males, children) }\end{array}$ \\
\hline $\begin{array}{l}\text { Association with } \\
\text { epilepsy }\end{array}$ & $\begin{array}{l}\text { Certain; evidence of a } \\
\text { causal relationship, } \\
\text { mostly from cross- } \\
\text { sectional studies }^{42-46}\end{array}$ & $\begin{array}{l}\text { Strong evidence for an association, } \\
\text { mostly from cross-sectional studies; } \\
\text { causality inferred on the basis of } \\
\text { clinical studies and some cohort } \\
\text { studies }^{72-75}\end{array}$ & $\begin{array}{l}\text { Evidence for an association } \\
\text { is available; causality is } \\
\text { plausible but awaits } \\
\text { confirmation }^{109-114}\end{array}$ \\
\hline
\end{tabular}


Table 2 | Secondary prevention of epilepsy after parasitic infection

\begin{tabular}{|c|c|c|c|}
\hline Status & Cerebral malaria & Taenia solium cysticercosis & Onchocerciasis \\
\hline $\begin{array}{l}\text { Evidence for } \\
\text { currently } \\
\text { available } \\
\text { approaches }\end{array}$ & $\begin{array}{l}\text { Antimalarials: evidence unavailable. } \\
\text { Placebo-controlled trials are considered } \\
\text { unethical, as prompt diagnosis and } \\
\text { treatment is widely accepted to prevent } \\
\text { cerebral complications. No trials of } \\
\text { early Vs delayed treatment have been } \\
\text { conducted } \\
\text { Antiseizure medications: phenobarbital } \\
\text { was shown to reduce the incidence of } \\
\text { convulsive seizures but no evidence for } \\
\text { prevention of epilepsy and might } \\
\text { increase short-term mortality } 55,56\end{array}$ & $\begin{array}{l}\text { Antihelminthics (albendazole } \\
\text { and praziquantel): might reduce } \\
\text { seizure recurrence in the short } \\
\text { term. Long-term impact not } \\
\text { studied }^{88,89,90} \\
\text { Antiseizure medications: reduce } \\
\text { seizure recurrence but are not } \\
\text { antiepileptogenic; optimal } \\
\text { duration of treatment is } \\
\text { uncertain } \\
\text { Corticosteroids: reduce seizure } \\
\text { recurrence in the short-term }\end{array}$ & $\begin{array}{l}\text { Indirect evidence for } \\
\text { efficacy of ivermectin, } \\
\text { based on reduced rates } \\
\text { of epilepsy in endemic } \\
\text { communities treated } \\
\text { regularly with this } \\
\text { drug }{ }^{160}\end{array}$ \\
\hline $\begin{array}{l}\text { Potential } \\
\text { novel } \\
\text { approaches }\end{array}$ & $\begin{array}{l}\text { Inhibition of cytoadherence by } \\
\text { antagonists of intracellular adhesion } \\
\text { molecule- } 1 \text {, which binds to } \\
\text { Plasmodium falciparum erythrocyte } \\
\text { membrane protein }{ }^{161} \\
\text { Drugs modulating expression of pro- } \\
\text { inflammatory cytokines, for example, } \\
\text { biological response modifiers such as } \\
\text { IL-1 receptor antagonists or tumour } \\
\text { necrosis factor (TNF) antagonists }\end{array}$ & $\begin{array}{l}\text { Calcium chelators to prevent the } \\
\text { development of calcification, for } \\
\text { example, dimercaprol, succimer } \\
\text { or D-penicillamine } \\
\text { Drugs modulating expression of } \\
\text { pro-inflammatory cytokines, for } \\
\text { example, biological response } \\
\text { modifiers such as IL-1 receptor } \\
\text { antagonists or TNF antagonists }\end{array}$ & $\begin{array}{l}\text { Broad-spectrum } \\
\text { immunological therapies }\end{array}$ \\
\hline
\end{tabular}


Table 3 | Primary prevention of parasitic infections

\begin{tabular}{|c|c|c|c|}
\hline Approach & Cerebral malaria & Taenia solium cysticercosis & Onchocerciasis \\
\hline Vector-directed & $\begin{array}{l}\text { Long-lasting insecticide- } \\
\text { impregnated bed nets, } \\
\text { residual indoor spraying }{ }^{59-} \\
62\end{array}$ & NA & 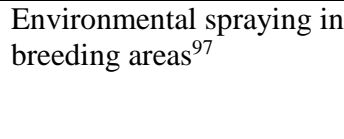 \\
\hline Agent-directed & Preventive chemotherapy $^{63}$ & $\begin{array}{l}\text { Human taeniasis: mass } \\
\text { taenicidal treatment }^{101} \text {, } \\
\text { targeted human taenicidal } \\
\text { treatment } \\
\text { Porcine cysticercosis: porcine } \\
\text { vaccination, porcine } \\
\text { chemotherapy (oxfendazole) }^{101}\end{array}$ & $\begin{array}{l}\text { Community-directed } \\
\text { periodic treatment with } \\
\text { ivermectin }^{133}\end{array}$ \\
\hline Host directed & $\begin{array}{l}\text { Community-based health } \\
\text { education }\end{array}$ & $\begin{array}{l}\text { Health education: community- } \\
\text { based or targeted to pig } \\
\text { farmers }^{102-104}\end{array}$ & $\begin{array}{l}\text { Community-based health } \\
\text { education }\end{array}$ \\
\hline
\end{tabular}

Fig. 1 | Global distribution of parasitic infections. World map depicting geographical areas with high levels of transmission of the three most common parasites associated with epilepsy, Plasmodium falciparum, Taenia solium and Onchocerca volvulus. Data from WHO Global Health Observatory Data Repository, REF. ${ }^{162}$, REF. ${ }^{163}$ and REF. ${ }^{164}$.

Fig. 2 | Life cycle and transmission of Plasmodium. Malaria is a typical vector-borne disease, transmitted by the bite of the female Anopheles mosquito. Several forms of the Plasmodium parasite are recognized, but $P$. falciparum is responsible for the most severe clinical manifestations, which can include cerebral malaria. The parasite is injected in to the human bloodstream during a bite and subsequently parasitizes red blood cells. The boxes in the figure indicate stages of the life cycle and transmission pathway that are amenable to interruption, thereby presenting opportunities for control or elimination of malaria. Adapted from REF. ${ }^{165}$.

Fig. 3 | Life cycle and transmission of Taenia solium. Taenia solium is a two-host life cycle zoonotic helminth ${ }^{166}$. The adult tapeworm inhabits the human intestine and sheds eggs in human faeces, which are then ingested by free-ranging pigs. The eggs develop into larvae or cysticerci, mainly in the muscle and subcutaneous tissues of pigs — a condition known as 
porcine cysticercosis. Consumption of raw or undercooked pork infested with cysticerci leads to adult tapeworm infestation in humans (known as intestinal taeniasis), thus completing the life cycle. Human cysticercosis occurs when humans become accidental hosts after ingesting food or water contaminated with $T$. solium eggs from self (autoinfection) or other (crossinfection) human carriers. The eggs transform to oncospheres, which migrate to the brain, muscles and subcutaneous tissues. The figure illustrates stages in the $T$. solium life cycle that can be interrupted and, hence, exploited for control or elimination of the parasite.

Fig. 4 | Life cycle and transmission of Onchocerca volvulus. The infective agent for onchocerciasis is Onchocerca volvulus, a filarial nematode transmitted through the bite of the blackfly Simulium ${ }^{167}$. The bite of this fly introduces $O$. volvulus larvae to the human host, where they transform to adult worms that are mostly found in subcutaneous tissues. The adults, in turn, release several hundred microfilariae daily. These microfilariae infest the skin but also migrate to other organs. Skin snip biopsies not only demonstrate the presence of the parasite but also quantify infection (microfilariae) load, which correlates well with clinical manifestations ${ }^{111,168}$. The cycle is completed when the blackfly bites an infected human and acquires microfilariae, which in turn transform into larvae, ready for further transmission. The figure shows how various measures can control or eliminate the parasite. Adapted from REF. ${ }^{169}$. 